Research Article

\title{
Shaking Table Tests on a New Antislide Pile under Earthquakes
}

\author{
Jie Lai $\mathbb{D}^{1},{ }^{1}$ Yun Liu $\mathbb{D}^{1,2}$ and Wei Wang ${ }^{1}$ \\ ${ }^{1} X i$ 'an Research Institute of High Technology, Xi'an 710025, China \\ ${ }^{2}$ Chongqing Industry Polytechnic College, Chongqing 401120, China \\ Correspondence should be addressed to Yun Liu; 2360605055@qq.com
}

Received 12 July 2020; Revised 20 December 2020; Accepted 4 January 2021; Published 18 January 2021

Academic Editor: Nhon Nguyen Thanh

Copyright (C) 2021 Jie Lai et al. This is an open access article distributed under the Creative Commons Attribution License, which permits unrestricted use, distribution, and reproduction in any medium, provided the original work is properly cited.

\begin{abstract}
A retaining form of a shock-absorbing antislide pile is proposed for slope engineering. A flexible material (shock-absorption layer) is filled in front of an ordinary antislide pile, which is used to absorb a large amount of seismic energy, thereby decreasing the transmission of seismic energy to the antislide pile. The flexible material thus reduces the seismic response, hence improving the aseismic capacity of the antislide pile. To verify the seismic performance of the shock-absorbing antislide pile, a shaking table contrast test was conducted and the results were compared with those from an ordinary antislide pile. The test results show that the flexible material absorbs a portion of the seismic deformation of the slip mass, decreasing the final displacement of the shockabsorbing antislide pile compared to that of the ordinary antislide pile, thereby reducing the sensitivity of the pile body to the displacement. Under the same conditions, the acceleration response of the slope body at the same height is lower for the shockabsorbing antislide pile than that for the ordinary pile, with the seismic performance of the former being superior to that of the latter. Furthermore, the shock-absorbing antislide pile is similar to the ordinary pile in terms of the dynamic earth pressure distribution form of the pile shaft; however, its value is relatively smaller, and the former exhibits better dynamic stress performance than the latter. The test results should prove useful for aseismic design of slopes.
\end{abstract}

\section{Introduction}

The underlying effects of earthquakes on underground structures mainly include two aspects: additional force and displacement. Using traditional methods often increases the aseismic capacity of such structures by increasing their rigidity from the perspective of stress [1]. This method has proven to be effective for small- and medium-size earthquakes. However, statistical data from the Wenchuan earthquake indicate that, in strong earthquakes, the rigid underground structures experience more serious damage [2]. Some examples are cracking of the tunnel lining, water bursts, faulting of the slab ends, and gravity-type retaining wall cracking and damage. The use of a rock-bolt framework, prestressed anchor cable antislide piles, and other structures with a shock-absorption mechanism improve seismic performance. Unlike the situation for ordinary earthquakes, a structural body under the action of high-intensity earthquakes tends to undergo large deformation. However, rigid structures are more sensitive to displacement and cannot withstand such large deformations in the event of an earthquake, thereby suffering structural damage more easily than nonrigid structures. A structure with a shock-absorption layer is effective in preventing the structure from entering the collapse state because of the ability of the material to resist large deformation in an earthquake and dissipate seismic energy.

Currently, ensuring the seismic safety of underground structures has become an imminent need for social and economic development. Several studies have been conducted on the dynamic characteristics of antislide piles. AlDefae and Knappett [3,4] demonstrated that the use of a discretely spaced row of piles could be effective in reducing the deformation of slopes in earthquakes. They used centrifuge tests to validate the dynamic effect relationship between the soil and the pile. Elahi et al. [5] presented a simple approximate pseudostatic method for estimating the maximum internal forces and horizontal displacements of a pile group located on a soil slope. Accordingly, the pile maximum moment and horizontal displacement were estimated for many practical cases. Tiwari et al. [6] collected topographic and subsoil exploration information from a 
reactivated landslide area and performed numerous seismic slope stability analyses. Liam [7] performed three levels of analysis to assess the postliquefaction stability of embankments and interpreted the stability of the slope of a dam using prestressed concrete piles via finite element analysis. In addition to the above-mentioned research on the seismic performance of common underground structures, some scholars have proposed approaches to improve the seismic performance of underground structures by absorption of seismic energy using vibration-absorptive materials [8-10]; their research has focused on tunnel energy dissipation from the aspects of theory and testing. Despite the productive results, there are few reports on the corresponding shockabsorption measures for slope-retaining structures.

Additionally, in slope-retaining structures, antislide piles have been applied extensively in engineering, owing to their flexible layout, strong antisliding ability, and convenient construction [11]. However, similar to other rigid retaining structures, large-sized antislide piles also exhibit a high sensitivity to deformation and difficulty in withstanding long displacements. Therefore, the retaining slope of an antislide pile under high-intensity, strong earthquakes poses potential safety risks. In this study, we propose a new antislide pile form (a shock-absorbing antislide pile), in which a flexible material is filled in front of antislide piles to act as a shockabsorption layer. By allowing a certain deformation of the earth mass at the upslope surface of the pile, the flexible material absorbs the seismic energy, and the shearing capacity of the earth mass is also exerted. This ensures the safety of the landslide mass under strong earthquakes.

To validate the seismic performance of the shock-absorbing antislide pile proposed here, a large-scale shaking table experiment was performed. The dynamic response law of the shock-absorbing antislide pile, dynamic stress distribution of the pile shaft, and seismic performance were obtained by comparison with an ordinary antislide pile. Finally, the research results should prove useful for aseismic design of antislide piles.

\section{Mechanism of Action for Shock-Absorbing Antislide Piles}

2.1. Characteristics of the Flexible Material. For an underground tunnel structure, a shock-absorption layer (expanded polystyrene (EPS)) is typically provided between the outer periphery of the lining and the surrounding rock. This is to separate the lining from the rock and provide a shockabsorption layer to reduce the seismic response of the lining. This is not the same for the shock-absorbing antislide piles considered in this study. In view of the stress characteristics at different positions of the antislide pile, the EPS material used should be a flexible vibration-absorptive material. Consequently, we chose an EPS with a density of $20 \mathrm{~kg} / \mathrm{m}^{3}$ and an elastic modulus of $5.11 \mathrm{MPa}$. Additional information about the chosen EPS material is listed in Table 1. The pile body below the slip zone is an embedded section, and, because of its good force performance, it does not require installation of a shock-absorption layer. The rear part of the pile shaft above the slip zone mainly bears the downslide thrust during the earthquake, and a shock-absorption layer
(EPS material) should be provided here. As the earth mass at the upslope surface of the pile shaft mainly serves as a resistance, no shock-absorption layer will be set up here. The specific positions are shown in Figure 1.

2.2. Shock-Absorption Principle of the Antislide Pile. In combination with the principle of shock absorption, it is assumed that the antislide pile retaining slope has an S-wave effect in the straight-up propagation direction. With the $y$ direction chosen as the vertical direction, the horizontal displacement of the mass point at time $t$ is [8]

$$
U_{x}=A \cos \left(w t-2 \pi \frac{y}{\lambda}\right),
$$

where $A$ is the amplitude and $\lambda$ is the wavelength.

When the antislide pile and slip mass do not have a relative displacement because of the particularly large flexibility of the former, the horizontal displacement curvature, $\rho$, of the antislide pile satisfies the equation

$$
\frac{1}{\rho}=\frac{\partial^{2} U_{x}}{\partial y^{2}}=-A\left(\frac{2 \pi}{\lambda}\right)^{2} \cos \left(w t-2 \pi \frac{y}{\lambda}\right) .
$$

Then, the bending moment $M$ and shear force $Q$ received by the antislide pile are

$$
\begin{aligned}
& M=\frac{E_{l} I_{l}}{\rho}=A E_{l} I_{l}\left(\frac{2 \pi}{\lambda}\right)^{2} \cos \left(w t-2 \pi \frac{y}{\lambda}\right), \\
& Q=\frac{\partial M}{\partial y}=A E_{l} I_{l}\left(\frac{2 \pi}{\lambda}\right)^{3} \sin \left(w t-2 \pi \frac{y}{\lambda}\right),
\end{aligned}
$$

where $E_{l}$ and $I_{l}$ are the elastic modulus and moment of inertia of the antislide pile, respectively.

When there is a relative displacement $U_{x}-U_{l}$ between the antislide pile and slip mass and the former is assumed to be an elastic foundation beam, the differential equation can be written as [8]

$$
E_{l} I_{l} \frac{\partial^{4} U_{l}}{\partial y^{4}}=P=K_{h}\left(U_{x}-U_{l}\right) .
$$

Similarly, the internal force of the shock-absorbing antislide pile is

$$
\begin{aligned}
& M^{\prime}=\frac{E_{l} I_{l}}{\rho}=E_{l} I_{l} \frac{\partial^{2} U_{l}}{\partial y^{2}}=A E_{l} I_{l} R^{\prime}\left(\frac{2 \pi}{\lambda}\right)^{2} \cos \left(w t-2 \pi \frac{y}{\lambda}\right), \\
& Q^{\prime}=\frac{\partial M}{\partial y}=A E_{l} I_{l} R^{\prime}\left(\frac{2 \pi}{\lambda}\right)^{3} \sin \left(w t-2 \pi \frac{y}{\lambda}\right),
\end{aligned}
$$

where $M^{\prime}$ and $Q^{\prime}$ are the bending moment and shear force of the shock-absorbing antislide pile, respectively; $U_{l}$ is the displacement of the shock-absorbing antislide pile; $R^{\prime}=\left[1-\left(E_{l} I_{l} / K_{h}\right)(2 \pi / \lambda)^{4}\right]^{-1}$ and the elastic coefficient of the elastic foundation beam is $K_{h}=\left(K_{1} K_{2} /\left(K_{1}+K_{2}\right)\right)$, where $K_{1}$ is the elastic coefficient of the antislide pile and $K_{2}$ is the elastic coefficient of the flexible filling material.

The internal force of the ordinary antislide pile is 
TABLe 1: Typical EPS mechanical parameters.

\begin{tabular}{lccc}
\hline Tensile strength $(\mathrm{MPa})$ & Bending strength $(\mathrm{MPa})$ & Compressive strength $(\mathrm{MPa})$ & Shear strength $(\mathrm{MPa})$ \\
\hline 0.25 & 0.32 & 0.0089 & 1.085 \\
\hline
\end{tabular}

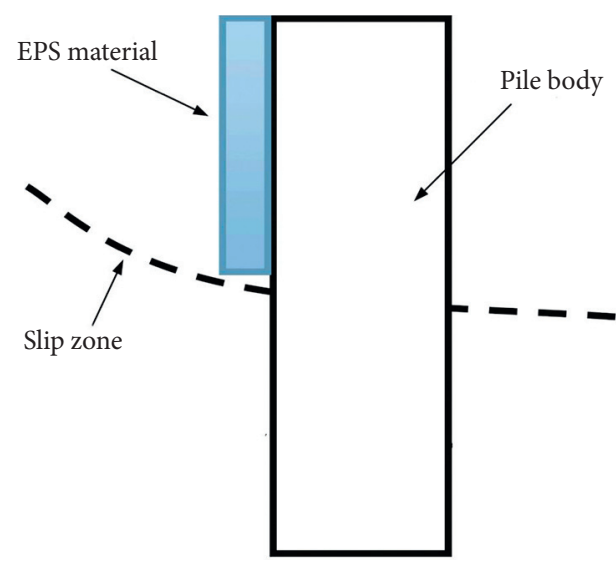

FIGURE 1: Shock-absorbing antislide pile damping schematic.

$$
\begin{aligned}
& M^{\prime \prime}=\frac{E_{l} I_{l}}{\rho^{\prime}}=E_{l} I_{l} \frac{\partial^{2} U_{l}^{\prime}}{\partial y^{2}}=A E_{l} I_{l} R^{\prime \prime}\left(\frac{2 \pi}{\lambda}\right)^{2} \cos \left(w t-2 \pi \frac{y}{\lambda}\right), \\
& Q^{\prime \prime}=\frac{\partial M}{\partial y}=A E_{l} I_{l} R^{\prime \prime}\left(\frac{2 \pi}{\lambda}\right)^{3} \sin \left(w t-2 \pi \frac{y}{\lambda}\right),
\end{aligned}
$$

where $M^{\prime \prime}$ and $Q^{\prime \prime}$ are the bending moment and shear force of the ordinary antislide pile, respectively, and $R^{\prime \prime}=\left[1+\left(E_{l} I_{l} / K_{l}\right)(2 \pi / \lambda)^{4}\right]^{-1}$.

The internal force ratio $K_{R}$ of the shock-absorbing antislide pile and the ordinary antislide pile satisfies the following condition:

$$
k_{R}=\frac{Q^{\prime}}{Q^{\prime \prime}}=\frac{M^{\prime}}{M^{\prime \prime}}=\frac{R^{\prime}}{R^{\prime \prime}}=\frac{1+\left(1 / K_{1}\right) E_{l} I_{l}(2 \pi / \lambda)^{4}}{1+\left(\left(1 / K_{1}\right)+\left(1 / K_{2}\right)\right) E_{l} I_{l}(2 \pi / \lambda)^{4}} .
$$

It can be seen from equation (7) that $<1.0$, which indicates that the internal force of the shock-absorbing antislide pile is less than that of the ordinary antislide pile.

\section{Model Test}

3.1. Experimental Setup. The test was performed on a shaking table in an open laboratory at the Institute of Engineering Mechanics, China Earthquake Administration. The shaking table used a three-way electrohydraulic servo drive, with the following basic parameters: The maximum load is 30 tons, and the maximum displacement that can be achieved is $50 \mathrm{~mm}$ in the $Z$ direction and $100 \mathrm{~mm}$ in the $X$ and $Y$ directions. The top of the shaking table is $5 \mathrm{~m} \times 5 \mathrm{~m}$, the maximum speed in the three directions is $0.5 \mathrm{~m} / \mathrm{s}$, and the maximum acceleration is $0.7 \mathrm{~g}$ in the $Z$ direction and $1.5 \mathrm{~g}$ in the $X$ and $Y$ directions. In the experiment, $X$ has the same tendency as the slope surface, and $Z$ is the vertical direction. The normal operating frequency of the shaking table is $0.5-50 \mathrm{~Hz}$.

3.2. Design of the Experimental Model. Figure 2 shows a schematic of the layouts of the two types of comparative piles. The left side is the new shock-absorbing antislide pile, which is filled with flexible material with a thickness of $1 \mathrm{~cm}$. The right side is an ordinary antislide pile for comparison. It has a pile length of $0.52 \mathrm{~m}(0.32 \mathrm{~m}$ in the upper part of the weak interlayer) and a section size of $0.06 \mathrm{~m} \times 0.08 \mathrm{~m}$; the pile spacing is $0.25 \mathrm{~m}$. The pile material is constructed by bonding with hard plastic plates, each with an elastic modulus of $1500 \mathrm{MPa}$. The flexible material (EPS) is an elastic foam plastic with an elastic modulus of $5.11 \mathrm{MPa}$. The flexible material is $0.32 \mathrm{~m}$ long, and the bottom of the material is located exactly at the slip zone.

In the shaking table test, the model box effect has a significant influence on the test results. To mitigate this adverse effect and ensure that the model box can reproduce the seismic response law of the free field for structures, we added polystyrene foam flexible material around the inner wall of the model box to absorb the boundary wave, thereby eliminating the corresponding boundary effect in the test [11].

The comparative test model is a single-row pile-reinforced slope with a height of $1.8 \mathrm{~m}$ and a slope angle of $23^{\circ}$. The model slope surface has six vertical accelerometers (with no accelerometers at points $G$ and $M$ ), eight horizontal accelerometers, and eight horizontal displacement meters, with the accelerometers operating at a frequency range of $0.1-100 \mathrm{~Hz}$ and a range of $0-5 \mathrm{~g}$. The horizontal displacement sensor records the relative displacement with respect to the shaking table with a resolution of $0.1 \mathrm{~mm}$. The monitoring points arranged on the ordinary antislide pile were recorded as $F, G, I$, and $J$ from the top of the slope, and the monitoring points on the shockabsorbing antislide pile were recorded as $L, M, N$, and $P$ from the top of the slope, as shown in Figure 3.

3.3. Selection of the Experimental Similarity Ratio. In mechanical models for geotechnical engineering, three methods-equation analysis, law analysis, and dimensional analysis-are frequently used to derive the similarity relationship. This experiment uses the gravity similarity law and dimensional analysis for the derivation. The length, density, and acceleration are selected as the basic controlled quantities, where $S_{l}=20, S_{\rho}=1$, and $S_{a}=1$. The remaining physical quantities are derived using the $\pi$ theorem, and the similarity ratio of the materials is obtained as listed in Table 2 [11-14].

It should be noted that, in the test, it is difficult to obtain completely similar materials owing to the limitations of the model size and material selection [11-15]. Based mainly on 


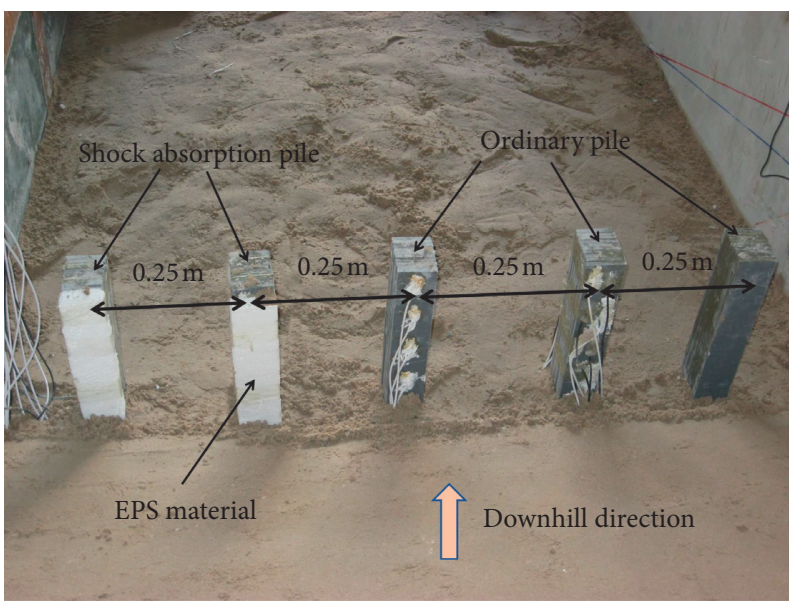

(a)

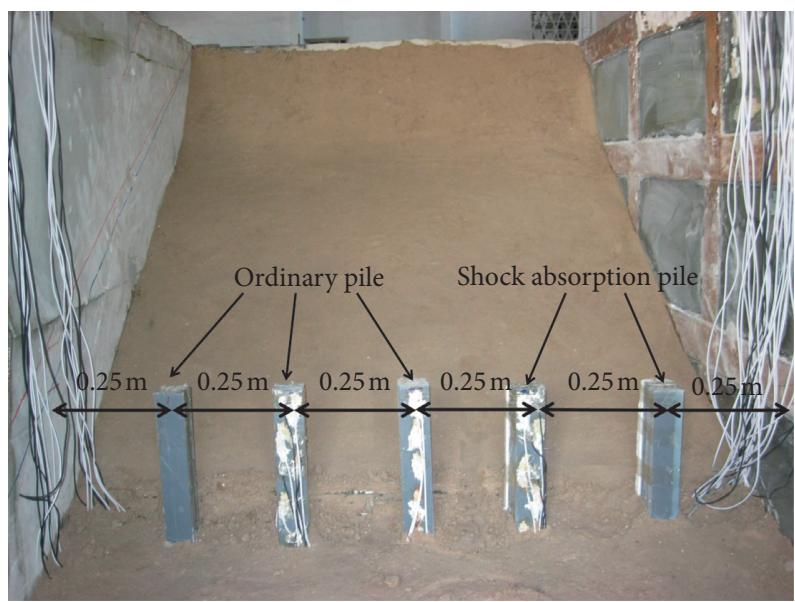

(b)

FIGURE 2: Schematic of the layout of a new type pile and ordinary pile: (a) top view; (b) front view.

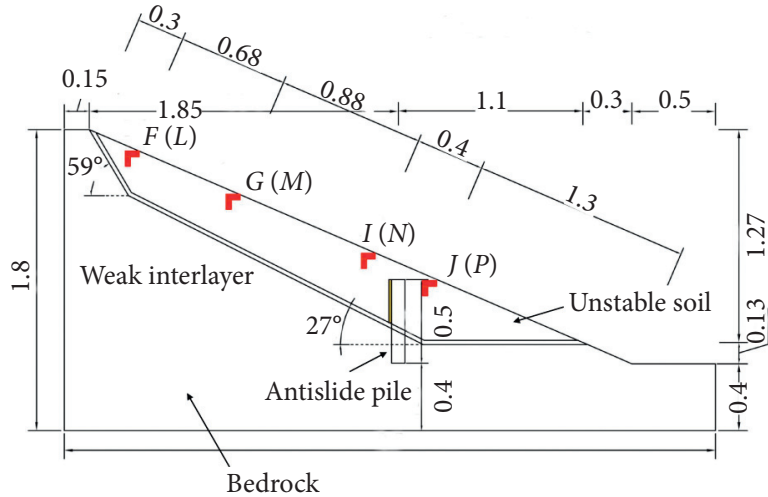

- Accelerometer

I Displacement meter

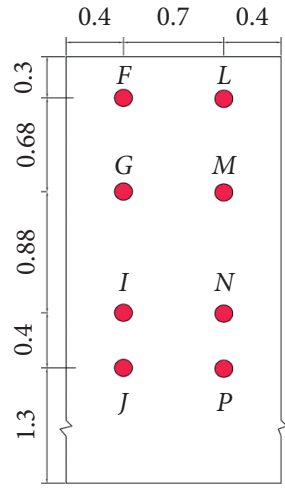

Monitoring points

(b)

Figure 3: Schematic of the antislide pile shaking table test model (in units of meters): (a) side view; (b) front view.

TABLe 2: Main similarity constant for the model.

\begin{tabular}{lcc}
\hline Physical quantity & Similarity relation & Similarity constant \\
\hline Density & $S_{\rho}$ & 1 \\
Length & $S_{l}$ & 20 \\
Elastic modulus & $S_{E}=S_{\rho} S_{l}$ & 20 \\
Strain & $S_{\varepsilon}=1$ & 1 \\
Acceleration & $S_{a}=\left(S_{E} /\left(S_{l} S_{\rho}\right)\right)$ & 1 \\
Internal friction angle & $S_{\varphi}=1$ & 1 \\
Cohesive stress & $S_{c}=S_{\rho} S_{l}$ & 20 \\
Time & $S_{t}=S_{l}\left(S_{\rho} / S_{E}\right)^{1 / 2}$ & 4.47 \\
Frequency & $S_{f}=1 / S_{t}$ & 0.223 \\
\hline
\end{tabular}

the research results of Lin et al. [14], this study focuses on structural damage and destruction and emphasizes the similarity of strength. In the test, the elasticity modulus is approximately similar; moreover, the stability of a geotechnical building near the failure stage is mainly controlled by friction. The cohesion has a limited influence on the structure, and the cohesion of the model can be much smaller than that of the prototype.

The geotechnical materials used in the test were standard sand, gypsum powder, talcum powder, glycerin, cement, and water as the basic materials. The relevant parameters were determined by relevant laboratory tests. The mix proportion and material parameters selected are given in Tables 3 and 4 .

3.4. Input Seismic Wave and Antislide Pile Monitoring Points. In the test, the Wenchuan seismic wave was selected as the excitation of the seismic response. The input peak value of the earthquake was applied stepwise from $0.1 \mathrm{~g}$ to $1.0 \mathrm{~g}$ to explore the influence of the seismic oscillation intensity. The input two-way seismic waves ( $X Z$ direction) were taken from the on-site monitoring data, where the horizontal direction ( $X$ direction) is the direction of the slope. Statistical data from the Wenchuan earthquake and related design specifications indicate that the vertical peak acceleration and 
TABLE 3: Model material mix.

\begin{tabular}{lcccccc}
\hline \multirow{2}{*}{ Materials } & \multicolumn{4}{c}{ Material mix ratio (\%) } \\
& Quartz sand & Gypsum & Talc & Cement & Water & Glycerol \\
\hline Sliding mass & 70.5 & 11.2 & 7.85 & 0.05 & 0.2 \\
Slip zone & 70.5 & 10 & 9.1 & 0.0 & 10.2 & 10.2 \\
Bedrock & 70.5 & 12 & 7 & 0.27 & 10.2 & 0.2 \\
\hline
\end{tabular}

TABle 4: Physical-mechanical parameters of model slope.

\begin{tabular}{lccccc}
\hline Materials & Density $\left(\mathrm{kg} / \mathrm{m}^{3}\right)$ & Elastic modulus $(\mathrm{MPa})$ & Poisson's ratio & Cohesive stress $(\mathrm{kPa})$ & Internal friction angle $\left(^{\circ}\right)$ \\
\hline Bedrock & 2390 & 35 & 0.21 & 54 & 34.6 \\
Slip zone & 2200 & 10 & 0.35 & 5 & 29 \\
Sliding mass & 2230 & 20 & 0.3 & 10.5 & 31.5 \\
Pile body & 2510 & $1.18 \times 10^{3}$ & 0.20 & Elastic material \\
\hline
\end{tabular}

horizontal ratio of the seismic oscillation are close to $2 / 3$ [16]. Therefore, the experimental vertical acceleration was loaded after the reduction of the horizontal peak by $2 / 3$. All the seismic waves were compressed with a time compression ratio of 1: $\sqrt{20}$, and the compressed $X$ direction waveform is shown in Figure 4. The information for each working condition is listed in Table 5.

3.5. Contrast of the Final Phenomena in the Test. To obtain the final degree of structural damage under the earthquake action in the test, we adopted a method of grading the loading. The intensity of the earthquake action was increased gradually, the development and evolution of the cracks in the shoring slope were monitored, and the final collapse state of the shoring slope after the test was obtained, as shown in Figure 5. As can be seen from the figure, the rupture surfaces of the two antislide pile-reinforced slopes after the earthquake are tension-shear rupture surfaces. This phenomenon coincides with that of the Wenchuan earthquake [16-18], and the manifestation of destruction differs significantly from traditional shear failure.

To compare the seismic effect of antislide piles, the horizontal displacements of monitoring point $F$ (which is on the side of the ordinary antislide pile) and monitoring point $L$ (which is on the side of the shock-absorbing antislide pile) were compared. From Figure 6, it can be seen that the horizontal displacement of the ordinary antislide pilereinforced slope was larger during earthquakes and reached $15.6 \mathrm{~mm}$ when peak ground acceleration $(P G A)=10 \mathrm{~m} / \mathrm{s}^{2}$, whereas the horizontal displacement of the shock-absorbing antislide pile-reinforced slope is $10.7 \mathrm{~mm}$. Obviously, the shock-absorbing antislide pile-reinforced slope exhibits better seismic performance.

To obtain the shock-absorption effect of the shock-absorbing antislide pile, the deformations of two types of antislide piles after an earthquake were recorded, as shown in Figure 7. As can be seen, the epicentral position displacement of the shock-absorbing antislide pile was $5.3 \mathrm{~cm}$ in the test, and the horizontal displacement of the ordinary antislide pile was $6.7 \mathrm{~cm}$. The displacement of the former is $20.89 \%$ less than that of the latter. This difference mainly occurs because the shockabsorbing antislide pile, with the flexible shock-absorption

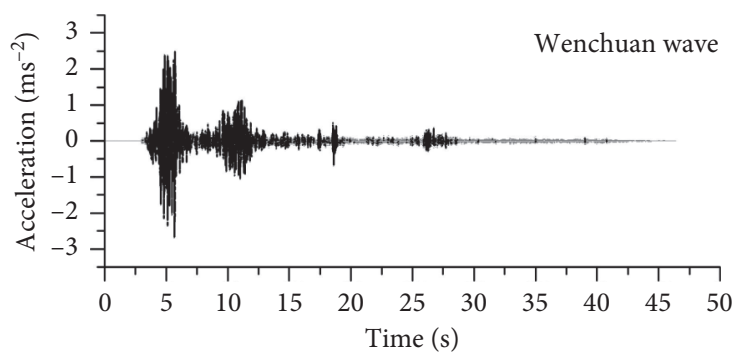

FIgURE 4: Horizontal seismic acceleration-time curve.

TABLE 5: Horizontal acceleration curve of input seismic waves.

\begin{tabular}{lcc}
\hline Working condition & Seismic wave types & $\begin{array}{c}\text { Input peak value of } \\
\text { earthquakes }(\mathrm{g})\end{array}$ \\
\hline 1 & White noise wave & $0.05 \mathrm{~g}$ \\
2 & Wenchuan wave & $0.1 \mathrm{~g} \mathrm{XZ}$ \\
3 & Wenchuan wave & $0.2 \mathrm{~g} \mathrm{XZ}$ \\
4 & Wenchuan wave & $0.3 \mathrm{~g} \mathrm{XZ}$ \\
5 & Wenchuan wave & $0.4 \mathrm{~g} \mathrm{XZ}$ \\
6 & Wenchuan wave & $0.6 \mathrm{~g} \mathrm{XZ}$ \\
7 & Wenchuan wave & $0.7 \mathrm{~g} \mathrm{XZ}$ \\
8 & Wenchuan wave & $0.8 \mathrm{~g} \mathrm{XZ}$ \\
9 & Wenchuan wave & $0.9 \mathrm{~g} \mathrm{XZ}$ \\
10 & Wenchuan wave & $1.0 \mathrm{~g} \mathrm{XZ}$ \\
\hline
\end{tabular}

polystyrene (EPS) material, allows a certain displacement of the earth mass at the upslope surface of the pile during the earthquake, absorbs the earthquake energy, reduces the displacement of the antislide pile structure itself, and maintains the bearing capacity of the antislide pile. This enhances the aseismic bearing capacity of the shock-absorbing antislide pile compared to that of the ordinary antislide pile.

\section{Comparison of Monitoring Data in the Test}

4.1. Comparison of Acceleration Responses at Monitoring Points. Figure 8 shows a comparison of the horizontal acceleration responses at the monitoring points of the two types of antislide piles at the same height (note that the data transmission line at point $P$ broke during the test, and the 


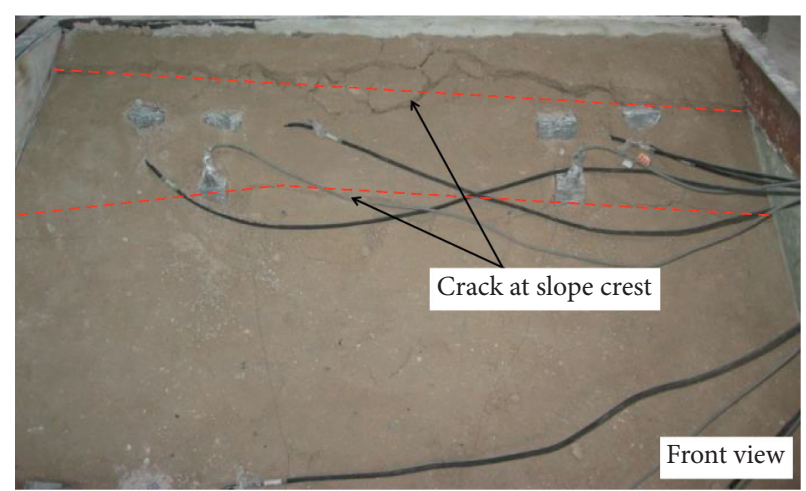

(a)

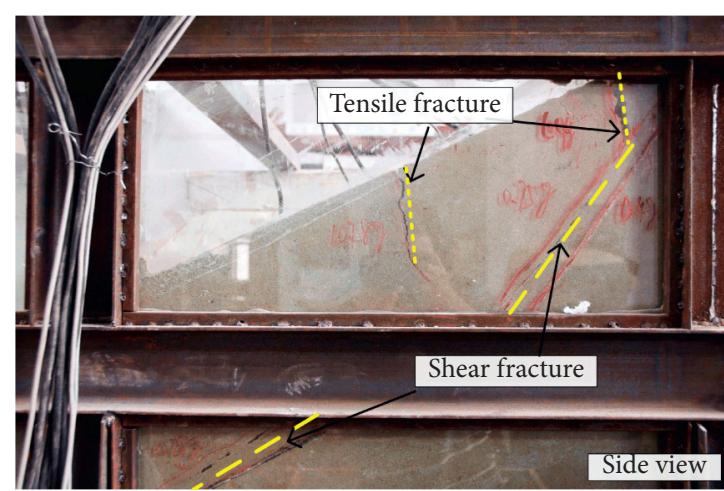

(b)

FIGURE 5: Final state of failure of the slope triggered by an earthquake: (a) front view; (b) side view.

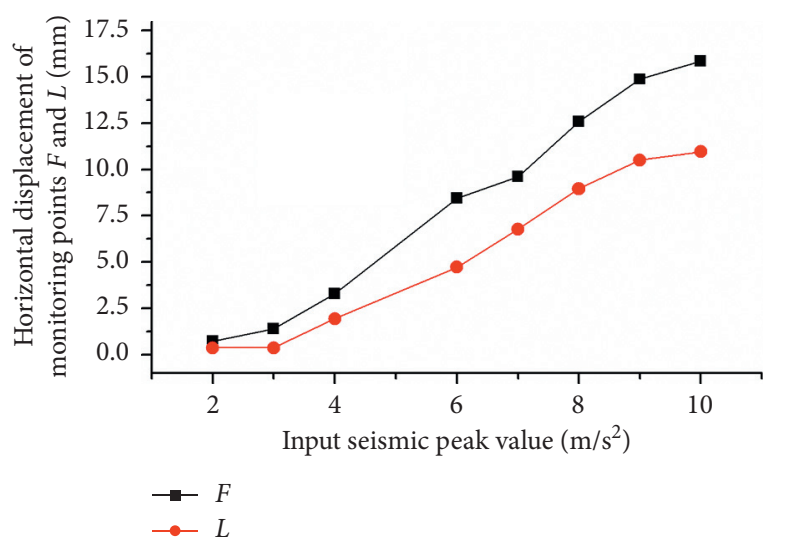

Figure 6: Horizontal displacement of monitoring points $F$ and $L$ at the top of the supported slope.

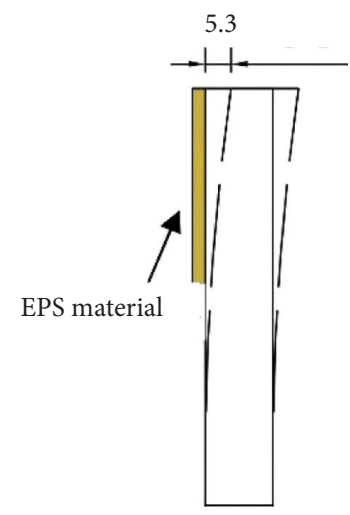

(a)

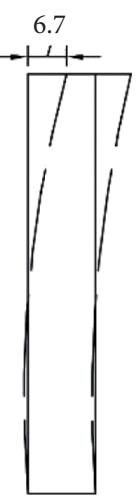

(b)
Figure 7: Diagram of position change of piles triggered by an earthquake. (a) Shock absorption pile. (b) Ordinary pile.

data were not collected.). For the shock-absorbing antislide pile, when the PGA of the input earthquake is $<9 \mathrm{~m} / \mathrm{s}^{2}$, the acceleration at the monitoring point is correspondingly larger than that of the input seismic wave. Furthermore, the higher the position of the monitoring point, the greater the acceleration response. When PGA $\geq 9 \mathrm{~m} / \mathrm{s}^{2}$, the acceleration response at monitoring point $L$ changes to some extent, but the value no longer increases. However, there is a downward trend after PGA $\geq 9 \mathrm{~m} / \mathrm{s}^{2}$, mainly because cracks appear in the slope, and their generation changes the acceleration response law of the slope.

For the ordinary antislide pile, when the PGA of the input earthquake is $<7 \mathrm{~m} / \mathrm{s}^{2}$, the acceleration at the monitoring point is correspondingly higher than that of the input seismic wave, and the higher the position of the monitoring point, the greater the acceleration. When PGA $\geq 7 \mathrm{~m} / \mathrm{s}^{2}$, the response increase at monitoring point $J$ is significant, exceeding that at monitoring $I$, with its value close to that at monitoring point $G$. The main reason for this is that, for the ordinary antislide pile, when the peak value of the input earthquake is $6 \mathrm{~m} / \mathrm{s}^{2}$, a crack occurs on the side slope of the shoring side slope of the ordinary pile. This crack changes the acceleration response law of the slope on the side of the ordinary pile.

Because both the ordinary antislide pile and shock-absorbing antislide pile are in a model box of the shaking table, the input seismic excitations are the same and the boundary conditions are consistent, with excellent comparability. As seen from the data, for both the retaining structures, with the increase in the earthquake action, the acceleration response at the monitoring points becomes increasingly noticeable. The higher the position of the monitoring points on the slope surface, the greater the acceleration response. Except for some point $M$ data, under the same conditions, the acceleration response of a monitoring point of the shock-absorbing antislide pile is less than that of the ordinary antislide pile by $9 \%-18 \%$. This difference can be attributed to the EPS material enabling a better aseismic effect for the shock-absorbing antislide pile.

4.2. Comparison of Dynamic Earth Pressure Responses of Pile Shafts. To compare the dynamic stresses of the two types of antislide piles under earthquake action, five earth pressure boxes and strain gauges were arranged on the front and rear sides of the pile shaft (Figure 9). Ten sets of earth pressure boxes and strain gauges were glued to the upslope and downslope surfaces of the pile to measure the dynamic earth pressure distribution on the pile. Figure 8 shows the position and specific number of earth pressure boxes and strain gauges; $A_{5}, A_{10}, A_{15}$, and $A_{20}$ are located in the slip zone. 


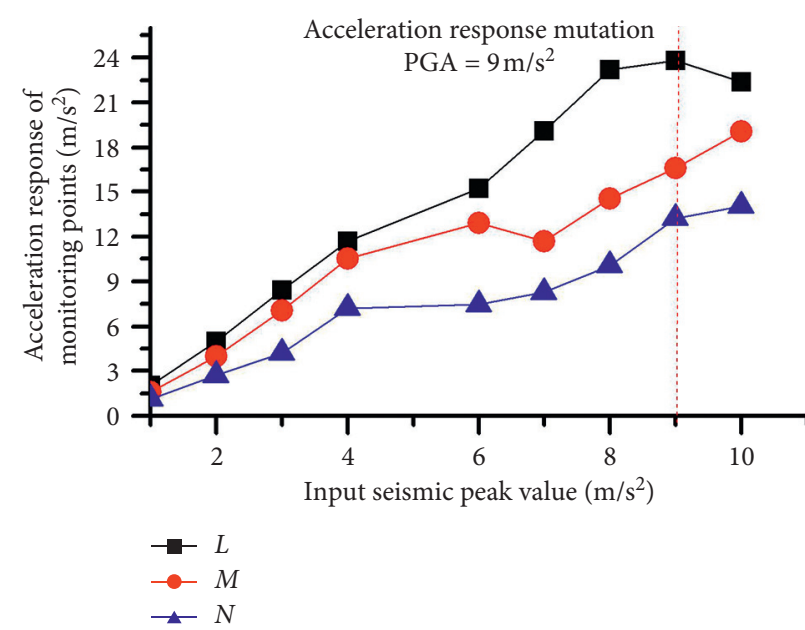

(a)

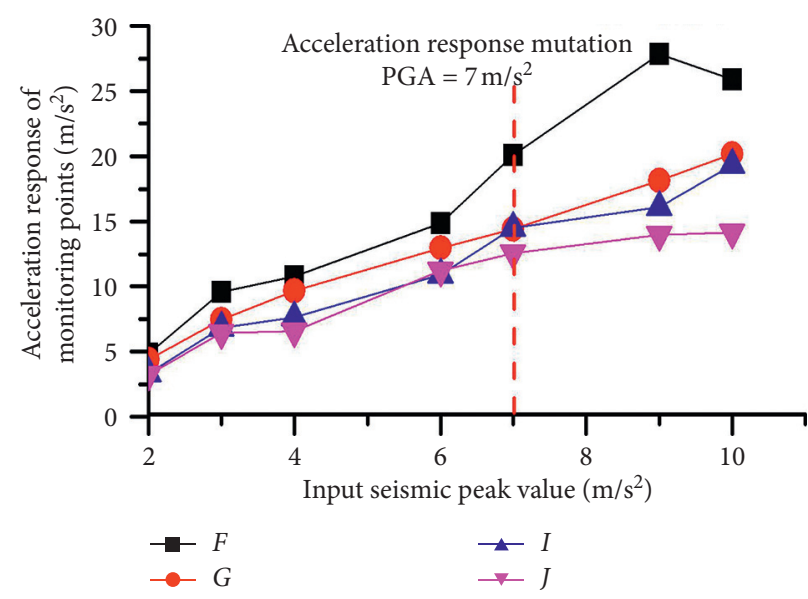

(b)

FIGURE 8: Comparison of the horizontal acceleration response at monitoring points of antislide piles: (a) shock-absorbing antislide pile, in which point $P$ broke during the test; (b) ordinary antislide pile.

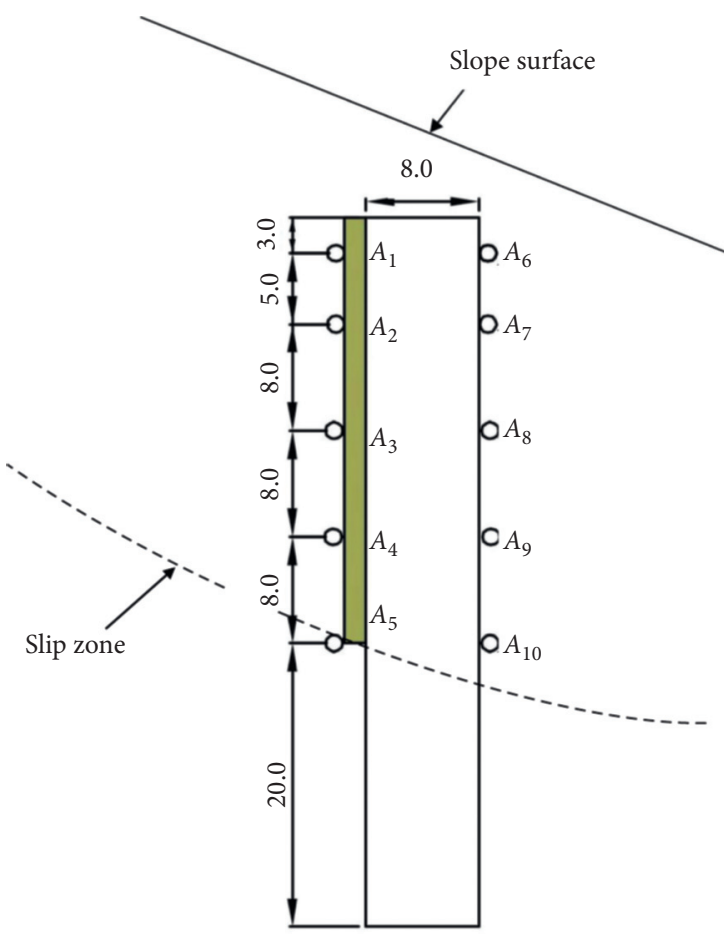

(a)

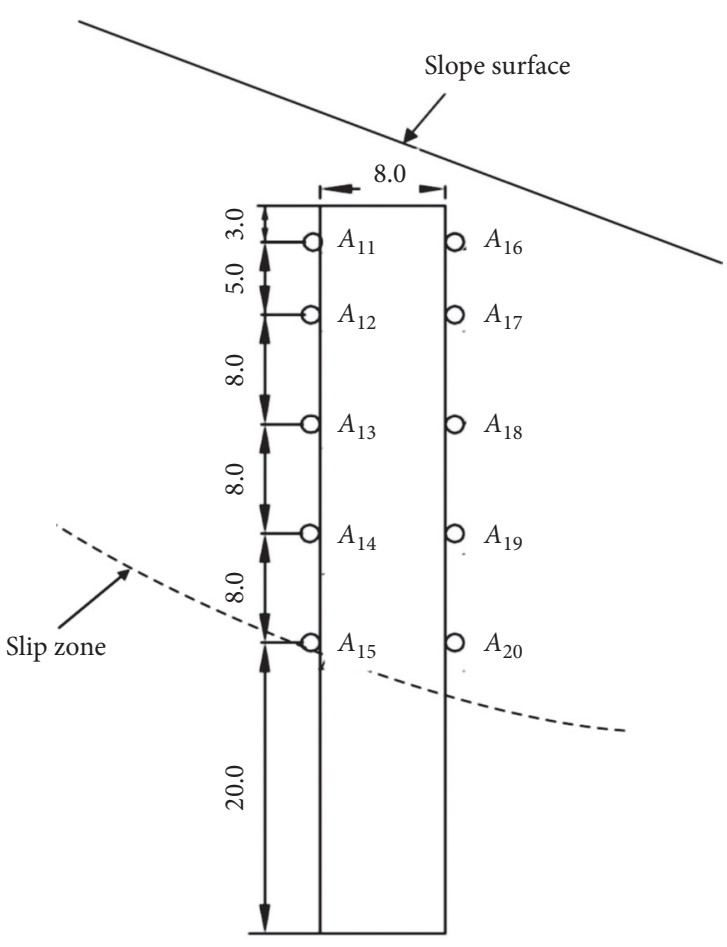

(b)

FiguRE 9: Layout of pressure boxes of antislide piles (in units of centimeters): (a) shock-absorbing antislide pile; (b) ordinary antislide pile.

It is worth pointing out that, as the input seismic amplitudes change from small to large in the test, the displacement and dynamic response of the pile shaft exhibit certain cumulative effects. To avoid the influence of this effect, the numerical values in the charts presented in this study are given as the values after deduction of the previous loading condition values.
Figure 10 shows the dynamic earth pressure history of monitoring point $A_{15}$ of the ordinary antislide pile under a $0.4 \mathrm{~g}$ seismic wave. As can be seen from this figure, the dynamic earth pressure of the pile shaft changes with time and reaches a maximum at $\sim 4 \mathrm{~s}$. To better compare the shock-absorption effect of the flexible material and meet engineering safety requirements, the distribution of the peak 


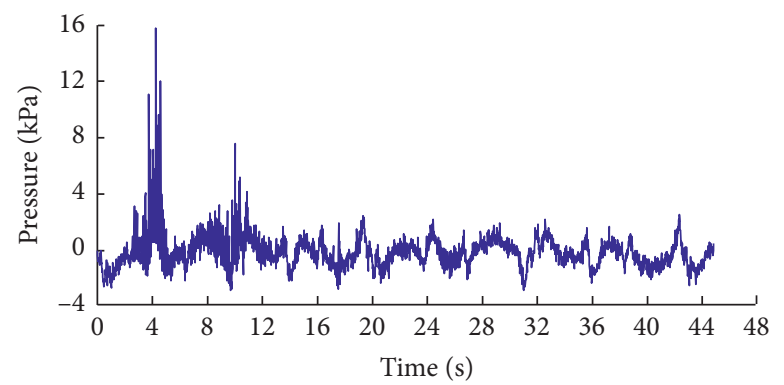

FIGURe 10: Dynamic earth pressure history of monitoring point $A_{15}(0.4 \mathrm{~g})$.

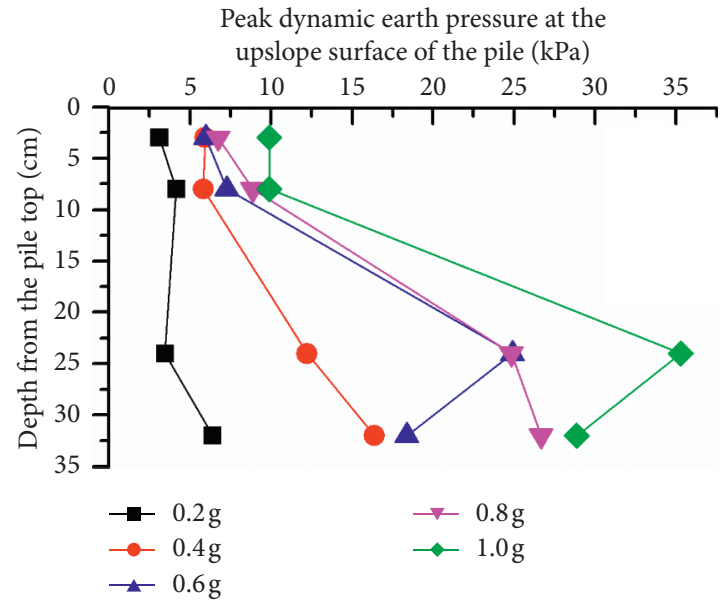

(a)

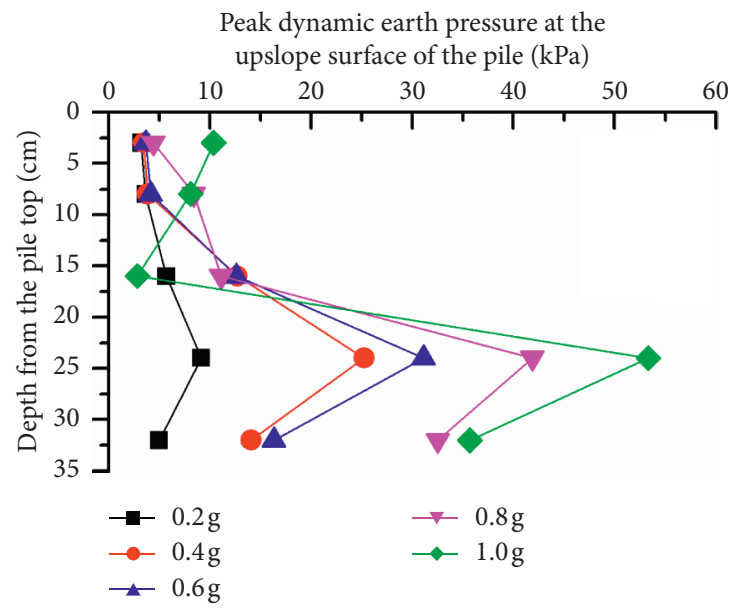

(b)

Figure 11: Peak dynamic earth pressure at the upslope surface of antislide piles: (a) shock-absorbing antislide pile, in which monitoring point $A_{3}$ is damaged; (b) ordinary antislide pile.

dynamic earth pressure at each monitoring point was analyzed.

\subsubsection{Dynamic Earth Pressure at the Upslope Surface of the} Pile. The magnitude of the dynamic earth pressure at the upslope surface of the pile represents the landslide thrust transmitted by the slip mass to antislide piles. According to the comparison chart of the peak dynamic earth pressure at the upslope surface of the two types of antislide piles (Figure 11), the magnitude of the dynamic earth pressure at the upslope surface of the pile is significantly affected by the peak value of the seismic wave and position of the monitoring point (note that, as the earth pressure box at measuring point 3 was damaged, no data were collected). With the increase in earthquake action, the dynamic earth pressure reaches a maximum in the middle-lower part of the pile near the weak interlayer. However, the dynamic earth pressure value at the top of the pile shaft is relatively small and the growth rate is not high. Under the same conditions, the dynamic earth pressure value of the shock-absorbing antislide pile is smaller than that of the ordinary antislide pile by $\sim 14 \%-33 \%$, as shown by the peak value. This difference occurs because, in the shock-absorbing antislide pile, the existing EPS material allows displacement of the slip mass, leading to exertion of the bearing capacity of the slip mass and reducing the landslide thrust to the shock-absorbing antislide pile. Therefore, the landslide thrust of the ordinary antislide pile is more obvious.

For the shock-absorbing antislide piles and ordinary antislide piles, the blocking effect of the antislide piles results in a change to the potential sliding surface of the slope and failure to slide according to the original weak interlayer. The direction is changed near the antislide pile, and a sliding surface develops toward the top of the antislide pile. Finally, overtopping damage may occur. Therefore, the dynamic earth pressure values of the monitoring points $A_{5}$ and $A_{15}$ near the slip zone should be smaller than the monitoring values corresponding to the monitoring points $A_{4}$ and $A_{15}$.

4.2.2. Dynamic Earth Pressure at the Downslope Surface of the Pile. The dynamic earth pressure mainly at the downslope surface of the pile acts to resist the landslide thrust from a stable slope mass [19], which is beneficial to antislide piles. The comparison of peak dynamic earth pressures at the downslope surface of the two types of antislide piles in Figure 12 shows that the magnitudes of the dynamic earth pressures at the downslope surface of the two types of antislide piles are very close to each other. The data indicate 


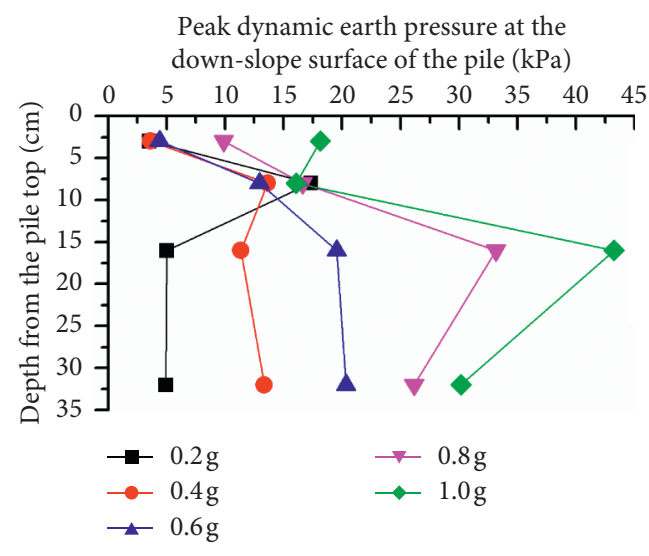

(a)

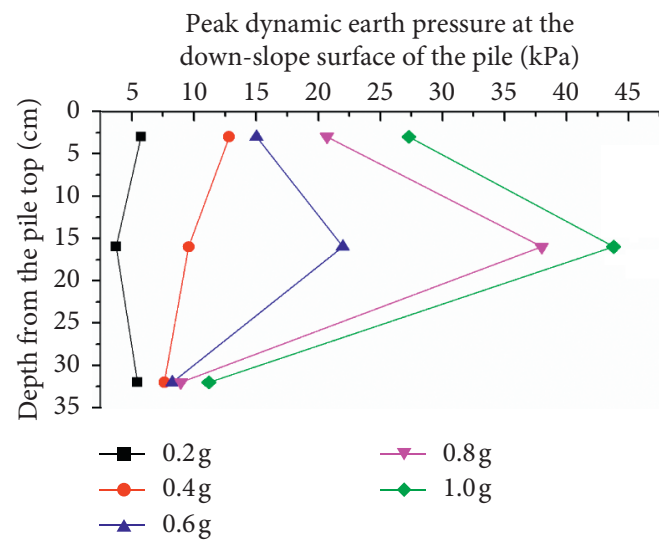

(b)

Figure 12: Peak dynamic earth pressure at the downslope surface of antislide piles: (a) shock-absorbing antislide pile, in which monitoring point $A_{9}$ is damaged; (b) ordinary antislide pile, in which monitoring points $A_{17}$ and $A_{19}$ are damaged.

that the shock-absorption layer of the shock-absorbing antislide pile does not affect the resistance before reducing the downslide thrust of the slip mass.

However, the dynamic earth pressure at the downslope surface of the pile is affected significantly by the peak value of the seismic wave and position of the monitoring points. The dynamic earth pressure at the downslope surface of the shock-absorbing antislide pile is mainly distributed in the middle-lower part of the weak interlayer, whereas that of the ordinary antislide pile is distributed in the middleupper part. The maximum dynamic earth pressures of the piles appear in the middle of the pile body. The main reason for this difference is that the sliding failure surface of the ordinary antislide pile-reinforced slope is expected to be generated before the shock-absorbing antislide pilereinforced slope, causing the ordinary antislide pile to be more susceptible to overtopping damage of the slip mass. Therefore, the earth mass resistance close to the back of the pile body is more fully exerted, resulting in its concentration in the middle-upper part of the ordinary antislide pile.

\section{Conclusion}

In this study, through shaking table experiments, the failure modes of the retaining slopes of shock-absorbing antislide piles and ordinary antislide piles, acceleration responses, and dynamic earth pressure distributions of pile shafts are compared. The following conclusions were drawn:

(1) Under earthquake action, the final failure surfaces of the reinforced slopes with the two types of antislide piles are not pure shear failures but consist of tension-shear fracture surfaces.

(2) After the earthquake action is completed, the EPS material (shock-absorption layer) in the shock-absorbing antislide pile absorbs some seismic energy and causes the final displacement of the pile to be smaller than that of the ordinary antislide pile. Therefore, the
EPS material reduces the sensitivity to displacement and improves the sensitivity of the antislide pile. The experimental results also account for the phenomena that occurred in the Wenchuan earthquake, where less destruction was caused by rock-bolt frames, prestressed anchor cable antislide piles, and other flexible retaining structures, and more damage was caused to rigid structures.

(3) For the two types of retaining structures, with the increase in earthquake action, the acceleration response of the monitoring point becomes more noticeable. The higher the position of the monitoring point on the slope surface, the greater the acceleration response. Except for a small amount of data, under the same conditions, at the same height, the acceleration response peak of a monitoring point of a shock-absorbing antislide pile is less than that of an ordinary antislide pile, indicating that the flexible material has some shock-absorption effect. Moreover, the seismic performance of the shock-absorbing antislide pile is better than that of an ordinary pile.

(4) The distribution forms of the peak dynamic earth pressures of the shock-absorbing antislide piles and ordinary antislide piles are similar. The EPS material of the shock-absorbing antislide pile does not affect the resistance at the downslope surface but reduces the downslide thrust of the slip mass, and the dynamic stress performance of the former is better. In addition, for both types of antislide piles, with the increase in earthquake action, the dynamic earth pressure of the pile shaft near the slip zone (weak interlayer) increases rapidly. Therefore, this part of the pile body needs to be strengthened during the aseismic design process.

\section{Data Availability}

The data used to support the findings of this study are available from the corresponding author upon request. 


\section{Conflicts of Interest}

The authors declare that they have no conflicts of interest.

\section{Acknowledgments}

This research was supported by the National Natural Science Foundation of China (51378496), the Science and Technology Research Program of Chongqing Municipal Education Commission (KJ1730413), the Chongqing Research Program of Basic Research and Frontier Technology (cstc2017jcyjAX0078), and the Youth Foundation of Rocket Force University of Engineering (2018QNJJ003 and 2020QNJJ011).

\section{References}

[1] D. P. Zhou, J. J. Zhang, and Y. Tang, "Seismic damage analysis of road slopes in Wenchuan earthquake," Chinese Journal of Rock Mechanics and Engineering, vol. 29, no. 3, pp. 565-576, 2010.

[2] L. K. Yao and Q. Chen, "New research subjects on earthquake resistant techniques of line engineering extracted from " 5.12 " Wenchuan earthquake," Journal of Sichuan University (Engineering Science Edition), vol. 41, no. 3, pp. 43-50, 2009.

[3] A. H. Al-Defae and J. A. Knappett, "Centrifuge modeling of the seismic performance of pile-reinforced slopes," Journal of Geotechnical and Geoenvironmental Engineering, vol. 140, no. 6, Article ID 04014014, 2014.

[4] A. H. Al-Defae and J. A. Knappett, "Newmark sliding block model for pile-reinforced slopes under earthquake loading," Soil Dynamics and Earthquake Engineering, vol. 75, pp. 265278, 2015.

[5] H. Elahi, H. G. Poulos, H. Hajimollaali, and A. Elahi, "Pseudostatic seismic response analysis of a pile group in a soil slope," Geotechnical and Geological Engineering, vol. 36, pp. 855-874, 2017.

[6] B. Tiwari, O. Jaime, and D. Shrestha, "Reduction in factor of safety for various landslide repair works with earthquake induced ground shaking," in Proceedings of the GeoFlorida 2010, pp. 3140-3148, Orlando, FL, USA, February 2010.

[7] F. W. Liam, "Post liquefaction deformation of embankments and effects on restraining piles," Journal of the Transportation Research Board, vol. 1633, pp. 19-25, 1998.

[8] M. N. Wang and G. Y. Cui, "Study of the mechanism of shock absorption layer in the supporting system of tunnels in highly seismic areas," China Civil Engineering Journal, vol. 44, no. 8, pp. 126-131, 2011.

[9] R. J. Bathurst and S. Zarnani, "Earthquake load attenuation using EPS geofoam buffers in rigid wall applications," Indian Geotechnical Journal, vol. 43, no. 4, pp. 283-291, 2013.

[10] P. Geng, J. L. Tang, and Q. L. Quan, C. He and Q. X. Yan, "Shaking table test for tunnel with shock absorption layer though fault zone," Journal of Central South University (Science and Technology), vol. 44, no. 6, pp. 2520-2526, 2013.

[11] C. D. Li, Study on Interaction Mechanism between Anti-Slide Pile and Landslide Mass and Pile Optimization, China University of Geosciences, Wuhan, China, 2009.

[12] S. Lai, "Similitude for shaking table tests on soil-structure fluid model in $1 \mathrm{~g}$ gravitational field," Soils and Foundations, vol. 29, no. 1, pp. 105-118, 1989.
[13] M. Z. Zhang, "Study of similitude laws for shaking table tests," Earthquake Engineering and Engineering Vibration, vol. 17, no. 2, pp. 52-58, 1997.

[14] G. Lin, T. Zhu, and B. Lin, "Similarity technique for dynamic structural model test," Journal of Dalian University of Technology, vol. 40, no. 1, pp. 1-8, 2000.

[15] J.-J. Zhang, J.-Y. Niu, X. Fu, L.-C. Cao, and Q. Xie, "Shaking table test of seismic responses of anchor cable and lattice beam reinforced slope," Journal of Mountain Science, vol. 17, no. 5, pp. 1251-1268, 2020.

[16] Y. H. Luo, "Study on complex slopes response law under earthquake action", Ph.D. Dissertation, Chengdu University of Technology, Chengdu, China, 2011.

[17] Q. Xu and R. Q. Huang, "Kinetics characteristics of large landslides triggered by May 12th Wenchuan earthquake," Journal of Engineering Geology, vol. 16, no. 6, pp. 721-729, 2008.

[18] F. Wang, Q. Cheng, L. Highland, M. Miyajima, H. Wang, and C. Yan, "Preliminary investigation of some large landslides triggered by the 2008 Wenchuan earthquake, Sichuan Province, China," Landslides, vol. 6, no. 1, pp. 47-54, 2009.

[19] H. L. Qu and J. J. Zhang, "Shaking table tests on influence of site conditions on seismic earth pressures of retaining wall," Chinese Journal of Geotechnical Engineering, vol. 34, no. 34, pp. 1227-1233, 2012. 